\title{
8
}

\section{Stakeholder Management}

In the field of corporate responsibility and sustainability, stakeholder management is maybe more relevant than many other issues companies have to take into account. There is no absolute agreement on what is a sustainable company and what is not—and many stakeholders have different opinions of what companies should do. Even peripheral stakeholders can have great impact on companies. This is an important consideration that companies need to be aware and take into account. In this chapter, I will explore the roles of different kinds of stakeholders such as owners (including investors), employees, governments, suppliers, customers, NGOs, and media. I will address the function of these stakeholders explicitly as well potential areas for positive collaboration. The power and impact of NGOs on corporations will receive special attention as they often act as representatives for environmental and social interests-and bring such issues to the attention of others.

Initially owners and investors were the key stakeholders in companies. The focus then was on procuring resources at low cost, producing at low cost, and achieving sales with quick profit. This worked in a time when employees had little power and owners had full control. There was no minimum wage, employees were often not allowed to organize, and there 
were limited regulations with regards to working hours and typically poor working conditions. Resources were often free or easy to appropriate while exploring new territories (e.g., the Gold Rush in the late 1800s). Many companies dumped their waste in rivers and oceans without penalty.

Gradually, employee-rights, regulations of working conditions, taxes on emissions, and so on changed the way of doing business. Now, with a complex and connected society, managing a variety of stakeholders' interests is an issue for corporations, especially with regards to sustainable development and responsibility.

For today's companies, responsibility must go beyond the boundaries of the firm and extend to their choice of business partners. This is also a crucial part of system change in a circular economy setting. Environmental and social issues throughout the supply chain also have to become part of a company's responsibility. The challenge of keeping track of and ensuring good working conditions is crucial.

Edward Freeman's stakeholder model from 1984, as presented in Chap. 2 (Fig. 2.5), is the "classic" stakeholder concept model. The model seems rather straightforward with the company in the middle circled by a variety of different stakeholders. In reality, the model is much more complex.

Today, there are many more and new stakeholders. In our digital society, new stakeholders such as Facebook, Twitter, and LinkedIn can have strong impact on corporations. Civil society can encompass different stakeholders, for instance, NGOs, with different goals and purposes. Furthermore, firms can have more of the same type of stakeholders in the model. For example, most companies do not have just one supplier but several. Finally, there is a direct connection between the different stakeholders, for instance customers are impacted by critical NGOs. So, the linkages are not only between the firm and the individual stakeholders in Freeman's model.

One thing is that there are many more stakeholders (Customer 1, Customer 2, Customer 3, etc.) in "the real world" and each of the stakeholders can have a different impact in terms of both size and scope. Finally, different stakeholders do not only relate to the company on an individual basis_-but can also have a dialogue between one another. A 
more realistic stakeholder model, which more accurately represents the complexity of a few selected stakeholders, is presented in Fig. 8.1.

Given the large range of stakeholders, not all can be included and taken into account. The challenge for the company is to listen to the "right" stakeholders in the right way and make the right decision depending on the topic. This is especially relevant when it comes to corporate responsibility for sustainability. Balancing different interests in the best way is eventually what forms the basis for a company's success or failure.

A company in a short-term horizon can narrow down the number of, and focus on, stakeholders. For instance, the customers of street vendors in tourist areas can be less concerned about product quality and trust among customers. If something goes wrong with the product the tourist has brought home, there are not many options for return and refund. The same is true when purchasing goods from low cost countries through eBay or other online platforms.

However, if a product is purchased from a brand name store close to where the customers live, the likeliness of confronting customer reactions is much higher. Furthermore, if journalists detect that the product is manufactured under poor working conditions in low cost countries or if

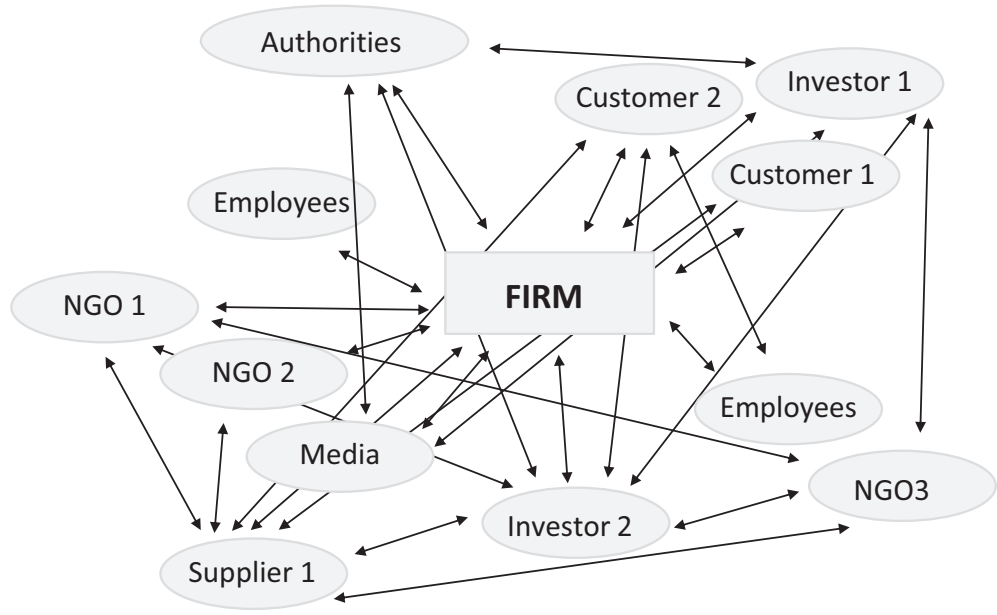

Fig. 8.1 Stakeholder model revised-in illustrating several versions of same stakeholder and dialogue between stakeholders 
authorities find that the products do not fulfil regulations, both can pose major challenges to the product brand. NGOs are often actors or stakeholders, which identify negative social and environmental elements associated with the production line of a product. That can be a risk and a threat for companies. At the same time, customers, media, and NGOs can be stakeholders, which can make positive contributions toward companies. They can rate similar products from different companies and recommend which are the best from an environmental and social perspective. This often guides customers in their purchasing process.

So, different actors agree that taking stakeholders into account is important, but how to do this in practice is less clear. In the rest of this chapter, I will take a closer look at the role and relevance of some more relevant stakeholders.

\subsection{Owners, Shareholders, and Managers}

How the company perceives it responsibility for society and sustainability depends upon the owners and the managers. In private companies, where the manager is often the owner, as is the case in many small-to-medium enterprises (SMEs), it is very much up to the manager how the company operates from a sustainability point of view. This also relates to the values of the owner. Some managers find sustainability to be relevant for the company and work on making products more sustainable, whereas other managers and owners do not care. In the same sector, companies can address sustainability issues very differently.

In companies with several owners, shareholders, it is less up to a hired manager, who is not an owner, to think about sustainability if the board of directors do not care. For some shareholders, the priority is short-term profit. Some have a limited investment perspective and speculate on a certain increase in shareholder price within a set timeframe. In this case, long-term payoffs for behaving sustainably might not be prioritized.

On the other hand, the company might have shareholders which require the company to behave in a certain way in order to invest. Environmental, Social, and Governance (ESG) requirements issues are increasingly relevant to shareholders. Relative to such shareholders, the 
company has to fulfil different sustainability requirements. A good example of how shareholders can change company focus happened in May 2021. The shareholders voted to replace two of the company's twelve board members with new climate concerned candidates. When the majority of the board of directors is dedicated to make the company more sustainable, the change can actually be realized. The shareholder perspective of sustainability issues will be closely addressed in the next chapter.

Companies registered on a stock exchange often have to report quarterly on results. The shorter the timeline for showing positive results, the more challenging it is to invest in better and more long-term sustainable technologies. This short time horizon is a major challenge and obstacle for companies to take measures to become more sustainable. When Paul Polman, CEO in Unilever 2009, decided not to issue quarterly earnings reports, there was an outcry. Later research has shown that increased frequency in reporting is associated with a decline in investments in US companies (Kraft et al., 2018). It is also evident that companies managed by equity companies with a longer investment horizon are also more keen on integrating sustainability for long-term profitability.

The Business Roundtable (BRT) is association formed in 1972 consisting of nearly 200 CEOs of leading American companies, together employing more than 15 million people. In line with most companies, the organization had defined the corporation's principal purpose as maximizing shareholder return. When BRT overturned its original purpose in 2019 , it received a lot of attention. Their new purpose statement was "companies should serve not only their shareholders, but also deliver value to their customers, invest in employees, deal fairly with suppliers and support the communities in which they operate" (Business Roundtable, n.d.). This statement has been welcomed by many stakeholders, while others have been critical and claim it is only window dressing. At the same time, ensuring sustainable business is in many cases a prerequisite for good and profitable business. Focus on short-term profit does not render profit in the long term.

The importance of the company sustainability work being anchored in the management team is addressed in Chap. 7. In addition, when it comes to sustainability, it is not enough that manager(s) claim that 
sustainability is important, they also have to behave sustainable themselves. They have to be good role models. If the CEO of public transportation urges people to commute on public transportation, the same CEO cannot commute with a gas guzzler herself. Sustainability needs to be integrated as part of the corporate culture (Ditlev-Simonsen, 2009).

\subsection{Employees}

Employees are key stakeholders for corporations. Their competence, knowledge, and experience are crucial assets. Without employees most companies would not survive-or not even exist. How companies treat their employees impacts among other, employees' motivation, trust, willingness to contribute, well-being, and commitment. Having committed employees is positive for retaining and avoiding expenses for recruiting new employees. " $55 \%$ of respondents said that strong sustainability programs improve morale, and 38\% said they increase loyalty" (Whelan \& Douglas, 2021).

How companies deal with society outside the company also impacts employees' attitude and performance. Sustainability issues such as to which extent the company is involved in pollution, levels of climate gas emissions, environmental and social issues in the supply chain, bribery, and so on all relate to employees. So, a company's level of social responsibility and sustainability is both relevant and important with regards to employees' perception of the employer and performance. In fact, research shows a perception of corporate social responsibility among employees is a significant predictor of affective commitment (Ditlev-Simonsen, 2012). Affective commitment again is associated with reduced absenteeism, better performance, and lower turnover.

More than 90 percent of the workforce claims to be willing to reduce wages for greater meaning at work (Achor et al., 2018). A large portion of the millennials claim that positive societal impact was more important than wages, and "societal impact and ethics are the most common reasons for millennials change their relationship with businesses" (Deloitte, 2019).

A challenge for companies is the fact that not all employees have the same perception of what a sustainable company, or employer, is. 
Companies have many different "types"/cultures and levels of employees, differences in ages, genders, cultures, and so on, that all impact perceptions of sustainability. Depending on employees' position, part-time, full time, interns, production operators, managers, directors, and so on, the view of sustainability and what is important can vary. Employees need to adhere to company values, but it might be even more important that they support their employer and how it operates.

When it comes to production and design, companies produce what sells. If employees in the production line do not like the design or color of a product, it is irrelevant as long as customers choose to buy the product - and as long as the product does not have significant negative societal or environmental impacts. When it comes to sustainability however, it involves more than values and beliefs. Having employees "on board" is therefore not as simple as producing products that sell. Therefore, it is important to involve employees in the process of developing a common sustainable attitude in the company.

Too often the decision on what is the scope of the sustainability strategy is made solely on the top. There are many examples of initiatives taken by top management for sustainability and responsibility engagement that part of the company workforce disagrees with. Most of the time this disagreement is not discussed openly, but it still exists and can impact employee work performance. Other times, employees' disagreement with employers have resulted in negative consequences for employers outside the company as well. Microsoft's support of the "Gay Rights Bill" was against some employees' beliefs. For them the fact that in the Bible it is stated that people of the same gender should not be partners was enough to make this a media case resulting in Microsoft withdrawing their support for the Bill (Kershaw, 2005).

Discussing the employee perspective of sustainability, the challenges of too much top-management-driven engagement are reoccurring. It is quite obvious that employee engagement is important; however, it is surprising how little attention is paid to it. One of the reasons for this may be that mangers implicitly assume that employees share their view and personal beliefs of what is important when it comes to sustainability and responsibility issues. That is one key reason for involving employees in the sustainability process (Ditlev-Simonsen, 2012). 
There are many examples of companies engaging in voluntary community work, involving employees and even giving them time off to contribute. This can be a positive experience for employees, both through feeling good for doing good, teaming up with co-workers, and good for society. However, this is not directly associated with doing business. Maybe the greatest potential of involving employees in the company work on sustainability is the potential for new and more sustainable production and products. Just as the "post-it" note was developed by a $3 \mathrm{M}$ employee, employees in most companies will have ideas related to sustainability-but they need to be asked and involved (Prather \& Turrell, 2002).

\subsection{Governments: The Public Sector}

The concept of the "tragedy of the commons" was first introduced in 1969 by the evolutionary biologist Garrett Harding. However, what it describes has been around since the beginning of time. The problem begins with the assumption that people act in their own self-interest and individuals take more common resources than they need without thinking of the long-term consequences. People in general are short-sighted and neglect societal interests in the pursuit of personal gains. The outcome can be devastating for everyone-including the next generation. This is not sustainable and therefore, we need regulations of common goods. A commonly cited example illustrating the "tragedy of the commons" is fishing in the ocean. If there were no regulations, people would catch as many fish as they could as fast as they could, eventually depleting stocks to extinction. To prevent overexploitation, fishing regulations have been put in place to preserve a balance ensuring availability of fish over the long-term. Still the regulations of common goods go too slow. The same applies to regulations related to climate issues and biodiversity in general. Governments thus need to regulate the use of common goods to ensure a fair distribution and well-being in countries, that is, sustainable development.

Historically, industrialization developed, faster than the regulatory regime, companies had to take on societal responsibility in order to get started and operate. Today, industries establishing businesses in developing countries or rural and unpopulated areas often need to take on 
responsibilities which are usually provided by public services in developed countries: housing, school, medical services, and so on for employees.

A good example of the development history of corporate responsibility is Norsk Hydro, a Norwegian company in the fertilizer sector established in 1907 in a small city in the middle of Norway, Rjukan. Today Hydro is Norway's largest employer. Prior to this startup, there were only a few farmers living in Rjukan, and the energy generating potential of large waterfalls was not realized. After three years of operations, there were 2200 people living in Rjukan, and in 1920 over 8000 people were living there. People moving to Rjukan to work could not afford housing, so this had to be provided by Norsk Hydro. This situation is often the same when companies are starting up in poor countries.

At that time in Norway, and similar to the situation in many poor countries today, a good public welfare framework is missing. For many of the employees coming to such sites, in the Norsk Hydro example in 1907 as well as in low cost countries today, the company owner has to take care of the workers. Norsk Hydro followed up on this responsibility and provided living conditions which were much better than where the employees came from, with indoor access to sanitation as well as health services. Not all companies starting up in low cost countries provide the same services to their employees today.

The following is another example of taking care of employers by Norsk Hydro. Rjukan is a narrow valley with steep mountains on the sides resulting in almost no sunlight during the winter. That is one reason why people did not want to live in Rjukan. However, the high mountain provided the waterfalls generating the energy for production, and having workers living there was a prerequisite for doing business there. In order to provide sun to the employees the founder of Norsk Hydro provided a cable-car lifting the employees almost 900 meters up to experience the sun, also during the winter. This is a good example illustrating how corporations have taken responsibility-beyond wages_-for employees. For Norsk Hydro providing such societal services was good for long-term profit as well. If the employees did not see the sun for several months or lived under poor conditions, they were more likely to get ill and not able to do their work, or unhappy which also impact negatively their work 
performance. Today, governments in developed countries have taken over most social service initiatives and financed these through taxes.

In developing countries with weak governments, the situation for companies is often similar to those in developing countries a century ago. Some companies use this as an opportunity for low cost production under poor conditions, whereas others take more responsibility for their employees. In this international setting, many companies also seek to reduce or avoid tax. Companies like Starbucks, which are working hard to portray themselves as sustainable companies, are criticized for avoiding tax in the UK (Bergin, 2012). The company claims that what it does is legal. Here reflecting on how far companies should go to use the system to increase profit from an ethical perspective is relevant to reflect on.

Still, companies and governments have realized that a closer dialogue is necessary in the pursuit of sustainable development and that publicprivate partnerships have contributed to positive experiences and sustainable outcomes (Spraul \& Thaler, 2019). Moving from companies opposing regulations from government, there is now a trend that in their pursuit of sustainability, companies are urging governments to pass stricter regulations. When companies try to go beyond what is required by government, for example by installing technologies which lead to less pollution, this can initially be costly. Competitors, which are not installing the same type of technology, can provide products at lower prices. In such instances, companies with better environmental performance urge government to set stricter requirements. This will be good for both business and the environment. Too often, the government regulations are behind what is technically possible with regard to environmental issues and prices of resources do not often cover the negative effects. It is argued that governments have the responsibility of representing "nature" as nature has no "voice". Subsiding the fossil fuels industry is an example of how governmental actions are negative for the environment and society as a whole (Coady et al., 2015; Shindell, 2015).

It is not only companies which are opposed to governmental regulations. When governments take initiatives to reduce the use of cars, with for example toll roads, major opposition from the groups and individuals is common. Introducing and increasing fees reduces the chances of political parties to be reelected — even when we are talking environmental taxation. 
Digital shopping has made it easy to buy low price products from low cost countries, like China. Digital platforms like eBay make it simple for individuals to purchase such production online. It is almost impossible to ensure that the produces are manufactured under good working conditions or determine their environmental impact. The low price implies a great challenge and unfair competition for manufacturers producing under good working conditions and environmentally friendly processes in a high-cost country. It is much easier to verify products from these companies with regards to working conditions and environmental issues in the supply chain. Still, when companies demand higher tolls and taxes on products imported from low cost countries by individuals, there is much opposition —and so regulators are slow to take measures to avoid such unsustainable behavior among individuals.

Free market and social democracy have led to many public services, such as the telephone network, managing roads, hospitals, and so on, which are run by private companies. In many cases, this has led to more social and environmentally friendly operations-but not always. Government's role in controlling such operations is becoming even more important at the same time as it is challenging.

An important contribution from governments and public institutions is to make and increase sustainability as part of their purchasing policy. In the OECD countries, one third of the total public spending is purchase of goods and services. Moves like the EU Green Public Procurement can contribute to a shift to more sustainable production. Furthermore, new EU requirements in the line of producers of certain electrical goods need to make their products repairable for at least 10 years. Still, it is often the price of not repair that outweighs the price of purchasing new products-not repair.

Still, the most important contribution to sustainability from governments is implementing public policy that makes business and individuals act in a more sustainable manner. Higher environmental taxes on primary raw materials and on waste, making it mandatory to use secondary raw materials in products, increase Extended Producer Responsibility, raise knowledge on sustainable production and consumption among people and companies are some examples of initiatives that would contribute to sustainability. 
Since there is a growing consensus that a carbon tax, so price on emitting carbon, might be the most effective tool in reducing emissions, governments have the power to decarbonize an economy. This implies they have a great responsibility. Increasing the price of $\mathrm{CO}_{2}$ emissions leads to increased energy efficiency. Today, carbon offsets are priced for less that $\$ 5$ USD per metric ton $\mathrm{CO}_{2}$, which does not provide the sufficient incentive for businesses or people to change enough. By taxing emissions and setting it sufficiently high, this induces change away from business as usual and investment into sustainable alternatives. However, by raising the cost of GHG emissions, it will also raise costs for businesses that will be later passed on to the consumer. For governments, this is a difficult policy initiative to promote. In developed countries, higher living expenses could mean the political party is voted out of office in the next election. In developing countries, a carbon tax is difficult because many are already living in poverty and can barely afford the basic necessities, never mind a carbon tax that would push even more people into poverty. So, will politicians act in self-interest to maintain power and do nothing or will they take the chance of being voted out for an unpopular carbon tax which is in the greater good for society and its future generations? The question remains.

\subsection{Suppliers}

As international trade has grown, import of goods and services has increased. Worldwide imports of goods and services were less than 14 percent in 1970 and have more than doubled today (The World Bank, n.d.). Improved transport efficiency and reduced cost have contributed to an increased global trade. The Nike case in Chap. 5 illustrates the challenges of moving manufacturing to low cost countries. Since then, we have learned a lot — and most large companies are working actively to avoid poor working conditions and child labor. Still, as the Rana Plaza case illustrates, production in low cost countries is too often proven to be under par. Figure 8.2 depicts the complexity of the supply chain concept, illustrated with a fraction of the number of suppliers which is usually the case for companies. 


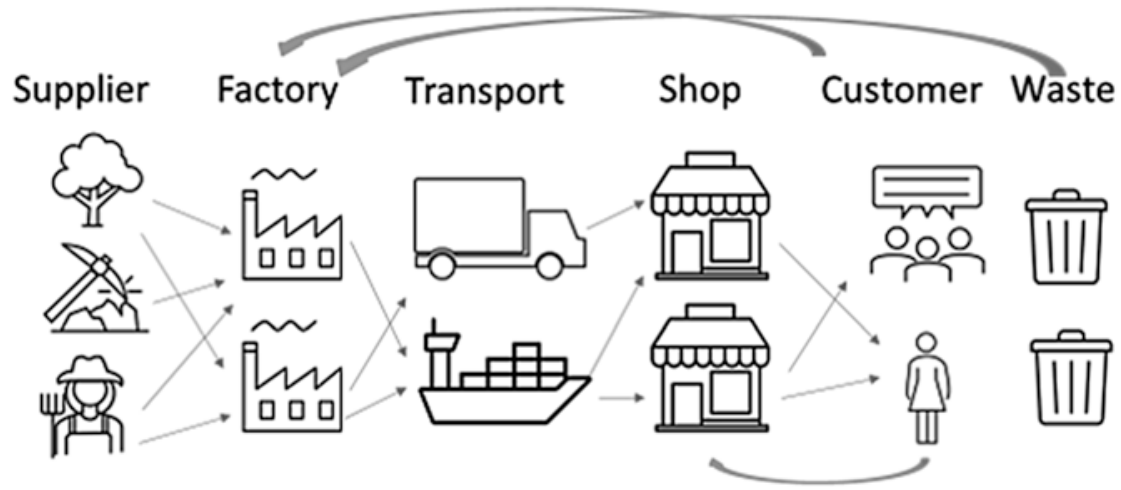

Fig. 8.2 Traditional supply chain-added circular reuse and return systems

Typical challenges in the supply chain are forced and slave labor, human trade, child labor, discrimination, lack of employees' rights, working conditions, right to get organized, wage and working hours. Environmental issues such as uncontrolled emissions and pollution are also a challenge. Large companies often have contracts with hundreds of suppliers which are hard to follow up. SMEs too can have several suppliers and for them travelling around to ensure acceptable working conditions and environmental performance are not affordable. Even with a signed supplier contract where good environmental and social issues are guaranteed, there is almost no way to control that the agreement is actually implemented. There are furthermore several incidents where large corporations have visited their suppliers' facilities and ensured good working conditions. Later it turns out that the facility, the company had visited was only a "show off" site, whereas the majority of products were manufactured at other sites not fulfilling the requirements. Actually, 65 percent of companies have limited knowledge of their supply below the factory tier of the supply chain (Blyth, 2020).

The Norwegian telecommunications company Telenor, which is partly own by the Norwegian government, has been very focused on taking a social responsibility. For 12 years, Telenor was rated among the top companies in the telecom sector on the Dow Jones Sustainability list. Yet, 
several times, unacceptable working conditions have been uncovered among suppliers in Bangladesh, even though the company had worked hard to avoid such incidents.

Often companies withdraw when unacceptable conditions are uncovered among suppliers. However, that might not be the best solution. Intuitively one would expect that children would not want to work and employees in general would not want to work overtime and on weekends. However, for seasonal workers, the main goal is to work as much as possible to earn as much as possible before they travel back to their families. They prefer to work and make money instead of having leisure time far away from their families. This is not only a challenge for seasonal workers in poor countries, carpenters from Poland and nurses from Sweden face the same challenge in Norway. They often want to work overtime but as that adds up to more hours than is allowed per week in Norway, this is not possible.

In the supply chain, social issues, like working conditions, receive most attention. Equally important in the supply chain are environmental challenges. Supply chains are responsible for about 90 percent of companies' environmental impact (Blyth, 2020). Just as it is hard to verify the social issues in the supply chain, it is equally hard to follow the environmental impact in the supply chain. Even though new human rights laws required companies to follow the supply chain and ensure quality with regards to social and environmental issues, acting upon this is a challenge. Goods such as cotton are traded on mercantile exchanges. In such incidents it is impossible to track the bushel of cotton back to the exact cottonfield it was produced.

Workers in low cost countries need knowledge with regard to their rights. Also talking with employees on the production floor, not only the management, gives one a better understanding of the working conditions present at the factory. Finally, companies can also work on providing long-term contracts with the suppliers - and time to plan. A challenge for suppliers is often that buyers want to test out new seasonal products, and, as soon as they learn what customers prefer, they want immediate delivery. That leaves the supplier and its employees in a challenging situation. In order to fulfil the order, unpaid overtime is often required. Justin-time production, that products are not produced before a buyer 
contract is signed, is often presented as a good solution from an environmental perspective. It implies less overproduction. On the other side, for seasonal products it often demands large production in short time-and overtime for employees.

Suppliers and especially distribution is crucial with respect to environmental issues. In a linear economy, as addressed in Chap. 6, the process is Take-Make_-Waste (Take-Make_-Use-Dispose). This is a one-way direction in which products end up as waste. In a circular economy, suppliers can, through Extended Producer Responsibility (EPR), be required to take back or collect products for reuse, repair, refurbish, remake, and so on. This will have a great impact on organizing the supply chain and changing the distribution system.

\subsection{Customers}

Companies need customers to survive. Customers in general claim to be increasingly concerned about the social and environmental quality of the products they purchase. More than half of the Norwegians say it is important to know where the goods they buy are produced and even more say they want to steer clear of companies that can be linked to human rights violations or unsustainable environmental management. Forty percent claim to have opted out of a product due to suspicion that the product contributes to child labor. But, when it comes to what the customers actually purchase, it is often not the most responsible product-but rather the product with the lowest price (Devinney et al., 2006; DitlevSimonsen, 2015).

According to a study investigating purchasing patterns in Norwegian clothing stores, customers hardly ever ask about environmental and social issues related to the products they purchase. Those who did ask were mainly interested in knowing whether parts of the product contained leather or skins-because they were vegetarians. At the same time, some of the employees thought that customers who were interested in environmental and working conditions would check the company's website in advance. Other studies found that some customers do not even want to know about ethical issues at the production stage because if that product 
does not meet ethical standards; it can result in unpleasant issues for the customer.

Companies have a great responsibility to produce products that are environmentally friendly. However, we as consumers also have a responsibility to choose sustainable products - and not buy too many of these but rather keep and use the products for a longer period. Authorities have a responsibility to make it profitable for companies to behave in a sustainable way-and that we as customers make the right choices.

It is not only the gap between attitude and behavior when it comes to purchasing patterns, but also the volume of shopping that is a problem when it comes to sustainability. Consumption among Norwegians has continuously grown. As addressed in the chapter on the circular economy, Norwegians have on average about 359 garments in their wardrobe. Many of these garments are rarely used and some of them have never been used. To show responsibility, many companies in the clothing industry respond with offers for renting garments as well as offers to repair garments. Nevertheless, so far, the majority of consumers are less interested in taking advantage of these offers, but this is gradually changing in a positive way. For a few companies, such offers have paid off, but for most, it is not profitable and more for posturing. With a change in attitude, this will be a good business in time. Online initiatives to purchase and sell used products, and simple ways to ensure secure payment and transportation have increased reuse of textiles, and are also contributing to developing a more circular culture.

Still, educating people on how to behave more sustainably is important. At finn.no ("find.no"), Norway's largest online trading site for used products, the purchaser can see how much $\mathrm{CO}_{2}$ was "saved" through purchasing the product used, not new. So far, few people know that how often we clean our clothing and whether or not we use cold or warm water have the second largest $\mathrm{CO}_{2}$ and water use impact of a pair of jeans, after the fiber production, according to Levi's. So in addition to purchasing more sustainable, it is a lot we can do for the environment in our consumer care of what we have purchased. 


\subsection{Non-Governmental Organizations}

A non-governmental organization (NGO) is a "voluntary group of individuals or organizations, usually not affiliated with any government ... formed to provide services or to advocate a public policy" (Karns, n.d.). There are currently thousands of international NGOs. Most are relatively small, but a few are quite large and powerful. These can set sustainability agendas, shape policy, and impact and convince individuals across the world-especially in a world where social media has great power. NGOs are usually nonprofit organizations and many of them work on environmental and social issues. NGOs can be divided into several groups, but in a sustainable setting, these two groups are the most relevant: charitable and service NGOs and participatory and empowering NGOs.

The first, charitable and service NGOs are organizations such as the Red Cross, CARE International, Médecins Sans Frontières (MSF), BRAC, and Oxfam. Their key activities initially involved collecting money to help others or save the environment. Some of these organizations are invaluable in their work during natural catastrophes and others also help people, plants/biodiversity, and animals in need.

During the last decades, it has become more common for such organizations to collaborate with corporations. A typical type of "collaboration" is one that companies, and employees donate money or products to the organization. But more constructive collaboration is also emerging. The Norwegian Red Cross for instance has several cooperative partners. These range from law firms working pro bono to a consulting company contributing with homework help and developing good IT solutions, construction companies building housing, telecom companies donating free use of mobile broadband as well as financial donations and volunteer work by employees. There has been a shift from pure donation of money to collaboration based on products and competence.

Another type of NGO, that goes beyond helping people in need, is a participatory and empowering NGO. These too can have the purpose of 
helping others; however, the approach is often different than that of charitable NGOs. Organizations like Amnesty international, Greenpeace and Bellona, World Wide Fund for Nature (WWF), and People for ethical treatment of Animals (PETA) are working more on lobbying, demonstrations, protest, and boycott to draw attention to different issues. Unfair treatment of individuals, unacceptable working conditions, environmental damage caused by corporations are typical issues these participatory and empowering NGOs engage in.

During the last few decades, these organizations have moved from merely criticizing corporations to collaborating with them on solutions. Sometimes it is a challenge to be both a partner and an opponent. Amnesty International for example invites companies to be project partners, supporters, and also to donate money. At the same time, the partner companies might unexpectedly be involved in unacceptable situations associated with social and environmental issues. This will be a challenge for both the NGO and the company. In situations like these, some NGOs choose to cancel the contract, whereas others collaborate with the company to improve the situation.

NGOs have great power to move opinions among individuals as well as governments especially through social media. The following are example illustrates this power.

Lego is a privately own Danish company producing plastic construction toys called Lego. The company was launched around 1950 and the brand as well as the product are well-known across the world. Since around 1960, Lego collaborated with Shell through Shell-branded toys and sold them at Shell gas stations. In 2012, Greenpeace launched the "Save the Arctic" campaign with the goal to stop oil drilling and as Shell was planning to drill in that area, Lego became a target for Greenpeace.

In 2014, Greenpeace launched a campaign against Lego. The argument was that Shell was damaging the future of the children by drilling and producing oil and that Lego supported this by collaborating with Shell. Lego had for a long time been recognized as a respected and 
responsible company working on energy efficiency and from their use of renewable energy, as well as alternatives to plastic to manufacture the toys. Even though Shell had partnerships and collaborations with several other companies and institutions, Greenpeace chose to focus the attack on Lego which was involved in producing toys for children-the next generation who will experience the negative consequences of global warming.

Greenpeace set up a campaign calling Lego to drop its collaboration with Shell. The NGO produced the two-minute film "Everything is not awesome". In the film, Greenpeace used Lego blocks to depict a Shell team drilling in the Arctic. Gradually, in the film, oil was covering the land and killing people and animals including polar bears. In the background, there is a sad song. This film is still available on YouTube and seen by almost nine million people. This way of portraying Lego and the resulting public awareness was very negative for the Lego brand. As a result, Lego eventually ended its partnership with Shell.

Most collaborations with NGOs and corporations have a positive effect. Whereas donations of money or products were the most common approach previously, partnership and collaboration are becoming more common. This type of collaboration can have a very positive effect for companies, the organizations, and society. This, however, requires a wellplanned and organized cooperation.

\section{How to Develop a Constructive Win-Win(-win) Partnership with a NGO?}

Collaboration between companies and NGOs must be anchored in a good strategy_along the lines of business in general. Previously, the relationship between companies and NGOs was characterized by philanthropy and donations. It was usually based on private initiatives with little focus on measuring impact and results. Oftentimes, NGOs were selected based on managerial preferences.

A partnership ought to start from the point where the company reviews it business and identifies NGOs that are relevant to the company's area of business. For a company involved in production in low cost countries, 
1. Select a cause
2.

Pick a partner
3.

Set goals
4.

Put assets to work
5.

Communicate
6.

Evaluate effect

Fig. 8.3 The revised model of NGO interaction (Ditlev-Simonsen, 2017)

supporting schools for children in the same area could be relevant collaboration with local NGOs. For service companies in big cities, jobtraining and internship programs for youth struggling with drugs can be an alternative example. Today, some companies actually invite NGOs to submit suggestions on how to collaborate and they choose the ones with the best and most constructive ideas.

After the partner is selected, the company and the NGO have to agree on the goals and metrics of the partnership are and how to reach them. For example, how many children are to attend school as a result of the project, how to evaluate what they learned, how many of the youth struggling with drugs managed to get a job, and so on. As the projects start, the partners have to communicate and share. Finally, the result of the collaboration needs to be evaluated. Did the project reach the goals? Evaluating the results is a valuable process with useful knowledge for further partnership. The collaboration model is presented in Fig. 8.3.

\section{How Corporations Collaborate with Different Stakeholders: Some Examples}

For large companies, it is common today to report on which stakeholders the company focuses on and how it engages with them. On the horizontal line, the company reveals how it communicates with these stakeholders. H\&M identifies the following ten stakeholders: customer, colleagues, 
communities, business partners, supply chain, industry peers, policymakers, NGOs, academia and science, and investors. The engagement is based on both formal and informal communication. Surveys in different formats are used to collect information. In this way, the company can get a broader understanding of stakeholders' concern. Issues like supply chain working conditions, environmental impact, peaceful conflict resolutions, product labeling and sustainability disclosures, microfibers and microplastics, and circular innovations are issues H\&M are working on with different stakeholders.

Huawei identifies customers and consumers, employees, suppliers, governments, NGOs, media and communities as key stakeholders. Huawei claims that working with stakeholders is an integral part of the company's sustainability work. In the matrix, presenting their stakeholder engagement, key concerns, communication channels, and Huawei strategy is presented. Also, here surveys, dialogue, training, participation at events, disclosure, and transparency are key issues through different platforms.

For Coca-Cola partnering for success is their approach to stakeholder engagement. Key stakeholder engagements presented are related to bottling partners, suppliers, consumers, and customers. Some examples of engagement include partnerships are directed to finding innovative ways to reduce packaging and waste and recycling education for communities.

Philip Morris International had grouped their 31 identified stakeholders into ten groups: adult consumers, employees, regulators, public health community, supply chain, retailers and wholesalers, business community, civil society, financial community and media. Means of engagement range from dialogue, surveys, training, formal gatherings, regular or ad hoc visits, hotline to call centers.

Listing stakeholders and forms of communication is common practice, but some companies take it a step further, to provide concrete results of their interaction. IKEA for example, pinpoints the important input they get through dialogue with stakeholders and how crucial the input from NGOs is for the company to make the right decisions. The World Wide Fund for Nature (WWF) is for example perceived as a key stakeholder and partner. The result of this collaboration includes among 
others a reduction of pesticide usage from almost 40 percent of their suppliers, reduction of water use by 37 percent, and an increase of gross margins of 24 percent (IKEA, 2021). The WWF can also be a critical organization. So, by establishing a positive working relationship early on helps IKEA avoid criticism from the WWF in the future.

\subsection{Other Stakeholder: Journalists, Social Media, Researchers, and More}

Finally, media is also a key stakeholder for companies. Often companies issue press releases on their positive sustainable behavior, but media is more interested in being critical and publishing negative coverage. There are many instances in which investigative journalists have uncovered breaches of laws and regulations.

The International Consortium of Investigative Journalists for example has uncovered several cases which have led to major changes in ways of doing business. Two examples include Walmart using widespread bribery to dominate the market in Mexico (Meyersohn, 2019; The Pulitzer Prizes, 2013) and the Paradise Papers in which the bank DNB facilitated tax evasion which led to the recovery of $\$ 1.3$ billion (McGoey, 2021).

Also, filmmakers produce documentaries uncovering and exposing unacceptable conditions. Heather White's Complicit is a good example. The film shares the story of a Chinese migrant worker's effort to eliminate life-threatening benzene from workplaces producing smartphones practices. More mainstream documentaries such as Super Size Me explore how unhealthy McDonald's food can be and also uncover the negative impact of corporations (Spurlock, 2004). Still, not all journalists and filmmakers do thorough research and the cases presented are not always portrayed in a balanced way. Cases involving negative issues can be blown out of proportion and often these cases become quite popular with readers. In this regard, researchers and academic institutions have a great responsibility in providing objective analysis. Many cases have also been uncovered through research which has led to positive changes. 


\section{Corporate initiatives to fight COVID-19}

The following examples of how companies responded to face COVID-19 challenges illustrate that companies are taking creative and constructive societal responsibility.

When COVID-19 was declared a pandemic in March of 2020, initially companies' main focus was on their own employees-how to ensure they did not get ill, and then to ensure financial security. Then the focus shifted, more than half of the world's population was under some form of lockdown, which impacted virtually every part of the economy and way of life. Companies have also donated large sums to help develop medicines and care for people in different ways. Many companies have also come up with creative positive initiatives illustrating social responsibility. Below are some examples:

Several companies, like Coca Cola, Hermes, and a Gin Producer, pivot factories to produce hand sanitizer.

Ventilux-emergency lighting specialist quickly launched temperature scanner, which can capture data in busy places such as shopping malls, hospitals, venues, and so on even wearing hats and masks.

Ford Motor Company-partnered with the United Auto Workers, GE Healthcare, and $3 \mathrm{M}$ lent manufacturing and engineering expertise to help build respirators and ventilators, assemble face shields, and use its 3D printing capacity to produce parts used in other personal protective equipment.

Coca Cola, McDonald's, Audi, and VW temporarily changed their logos to promote social distancing.

Scania-heavy truck maker, partnered with Karolinska University Hospital and is converting trailers into mobile testing stations and directed some 20 highly skilled purchasing and logistics experts to locate, acquire, and deliver personal protective equipment to health care workers.

Cozy - a restaurant in Vilnius, Lithuania placed of mannequins on seats, helping to ensure customer distancing while making the restaurant seem busy. The mannequins were dressed by local designers to advertise their clothing lines.

DAKA-Tyrol, Austria based waste-disposal company, repurposed snow cannons for disinfecting large areas like train stations or production halls.

Uber-expanded the services on offer and is now delivering products such as medication.

Doctolib-French tech company that develops appointment-scheduling software, offered free-of-charge service to French and German doctors, leading to 2.5 million online appointments.

Nike-when stores closed, staff engaged with Chinese consumers digitally by offering at-home workouts.

EasyJet and Virgin Atlantic-staff members were offered jobs in temporary NHS Nightingale hospitals.

McDonalds-in Germany created an employee-leasing agreement with Aldi grocery stores to help with surging demand, while the restaurant was closed. 


\section{References}

Achor, S., Reece, A., Kellerman, G. R., \& Robichaux, A. (2018). 9 out of 10 people are willing to earn less money to do more-meaningful work. Harvard Business Review Digital Articles, 1-7. https://hbr.org/2018/11/9-out-of-10people-are-willing-to-earn-less-money-to-do-more-meaningful-work

Bergin, T. (2012, October 15). Special Report: How Starbucks avoids UK taxes. Reuters. https://www.reuters.com/article/us-britain-starbucks-tax-idUKBRE 89E0EX20121015

Blyth, N. (2020). Sustainable development goals and the business community. DailyFT. http://www.ft.lk/opinion/Sustainable-development-goals-and-thebusiness-community/14-695549

Business Roundtable. (n.d.). One year later: Purpose of a corporation. https:// purpose.businessroundtable.org/

Coady, D., Parry, I. W. H., Sears, L., \& Shang, B. (2015). How large are global energy subsidies? IMF Working Paper, 15 (105). https://www.imf.org/exter$\mathrm{nal} / \mathrm{pubs} / \mathrm{ft} / \mathrm{wp} / 2015 / \mathrm{wp} 15105 . \mathrm{pdf}$

Deloitte. (2019). The Deloitte global millennial survey 2019. https://www2. deloitte.com/content/dam/Deloitte/global/Documents/About-Deloitte/ deloitte-2019-millennial-survey.pdf

Devinney, T. M., Auger, P., Eckhardt, G., \& Birtchnell, T. (2006, Fall). The other CSR: Consumer social responsibility. Stanford Social Innovation Review. https://doi.org/10.2139/ssrn.901863

Ditlev-Simonsen, C. D. (2009). Fordrer det noe spesielt å lede en samfunnsansvarlig bedrift. Magma, 2, 22-33.

Ditlev-Simonsen, C. D. (2012). The relationship between Norwegian and Swedish employees' perception of corporate social responsibility and affective commitment. Business \& Society, 54(2), 229-253. https://doi.org/10.1177/ 0007650312439534

Ditlev-Simonsen, C. D. (2015). The gap between attitude and behavior in environmental protection-the case of Norway. In P. E. Stoknes \& K. A. Eliassen (Eds.), Science based activism. Fagbokforlaget.

Ditlev-Simonsen, C. D. (2017). Beyond sponsorship-exploring the impact of cooperation between corporations and NGOs. International Journal of Corporate Social Responsibility, 2(6). https://doi.org/10.1186/s40991-017-0017-9

IKEA. (2021). IKEA culture and values. https://about.ikea.com/en/about-us/ ikea-culture-and-values 
Karns, M. P. (n.d.). Nongovernmental organization. Encyclopedia Britannica. https://www.britannica.com/topic/nongovernmental-organization

Kershaw, S. (2005). Microsoft comes under fire for reversal on gay rights bill. The New York Times. https://www.nytimes.com/2005/04/22/us/microsoftcomes-under-fire-for-reversal-on-gay-rights-bill.html

Kraft, A. G., Vashishtha, R., \& Venkatachalam, M. (2018). Frequent financial reporting and managerial Myopia. The Accounting Review, 93(2), 249-275. https://doi.org/10.2308/accr-51838

McGoey, S. (2021). Panama papers revenue recovery reaches $\$ 1.36$ billion as investigations continue. ICIJ International Consortium of Investigative Journalists. https://www.icij.org/investigations/panama-papers/panamapapers-revenue-recovery-reaches-1-36-billion-as-investigations-continue/

Meyersohn, N. (2019). Walmart settles with US government over international bribery. CNN. https:/edition.cnn.com/2019/06/20/business/walmartbribery-mexico-brazil-fcpa-sec

Prather, C. W., \& Turrell, M. C. (2002). Managers at work: Involve everyone in the innovation process. Research-Technology Management, 45(5), 13-16.

Shindell, D. T. (2015). The social cost of atmospheric release. Climatic Change, 130(2), 313-326.

Spraul, K., \& Thaler, J. (2019). Partnering for good? An analysis of how to achieve sustainability-related outcomes in public-private partnerships. Business Research, 13, 1-27.

Spurlock, M. (2004). Super Size Me [Film]. https://www.imdb.com/title/ tt0390521/

The Pulitzer Prizes. (2013). The 2013 Pulitzer prize winner in investigative reporting: David Barstow and Alejandra Xanic von Bertrab of The New York Times. https://www.pulitzer.org/winners/david-barstow-and-alejandraxanic-von-bertrab

The World Bank. (n.d.). Imports of goods and services (\% of GDP): 1960-2019. https://data.worldbank.org/indicator/NE.IMP.GNFS.ZS

Trove Research. (2021). Ten-fold increase in carbon offset cost predicted, UCL web June 4th, 2021 https://www.ucl.ac.uk/news/2021/jun/ten-fold-increasecarbon-offset-cost-predicted

Whelan, T., \& Douglas, E. (2021). How to talk to your CFO about sustainability. Harvard Business Review, 99(1), 86-93. 
Open Access This chapter is licensed under the terms of the Creative Commons Attribution 4.0 International License (http://creativecommons.org/licenses/ by/4.0/), which permits use, sharing, adaptation, distribution and reproduction in any medium or format, as long as you give appropriate credit to the original author(s) and the source, provide a link to the Creative Commons licence and indicate if changes were made.

The images or other third party material in this chapter are included in the chapter's Creative Commons licence, unless indicated otherwise in a credit line to the material. If material is not included in the chapter's Creative Commons licence and your intended use is not permitted by statutory regulation or exceeds the permitted use, you will need to obtain permission directly from the copyright holder.

(c) (i) 